\title{
The Crystal Structure and the Conformation of
} 1,3,5-Triacetoxyhexahydro-1,3,5-triazine

\author{
BODIL JERSLEV, LOTTE BREHM and MARTIN VAHL GABRIELSEN *
}

Royal Danish School of Pharmacy, Department of Chemistry BC, Universitetsparken 2, DK-2100 Copenhagen, Denmark

Dedicated to Professor K. A. Jensen on his 70th birthday

The crystal structure of acetylated "triformoxime" has been studied. The proposed molecular structure 1,3,5-triacetoxyhexahydro1,3,5-triazine was definitely proved. The monoclinic crystal structure, space group $C 2 / c$, was determined from three-dimensional MoK $\alpha$ $\mathrm{X}$-ray diffraction data. The structure was solved by direct methods and refined by fullmatrix least-squares techniques to an $R$. value of 0.043 . In the crystal structure the heterocyclic ring has a flattened chair conformation with the three substituents in axial positions. The average ring dimensions are: $\mathrm{C}-\mathrm{N}=1.458 \quad \AA, \angle \mathrm{CNC}=111.4^{\circ}$ and $\angle N C N=118.2^{\circ}$. The geometry of the hexahydro-1,3,5-triazine ring is discussed in relation to the ideal conformation proposed. ${ }^{7}$ In the $O$-acylated hydroxylamine moiety the arrangement of the $\mathrm{C}=\mathrm{O}$ and the $\mathrm{O}-\mathrm{N}$ bonds is cisoid. The average $\mathrm{C}=\mathrm{O}$ bond is $1.189 \AA$. Only few short inter-molecular contacts are formed, but a number of polar attractions between carbonyl oxygen atoms and hydrogen atoms contribute to the stabilization of the crystal structure.

The molecular structure of acetylated "triformoxime" has been studied by Jensen and Holm. ${ }^{1}$ Their results strongly support the proposed formula 1,3,5-triacetoxyhexahydro1,3,5-triazine, but they suggested that a crystal structure determination of the compound should be carried out with the purpose of obtaining an unequivocal confirmation of the molecular structure.

* Present address: Hvidovre Hospital, Kettegårds Alle 30, DK-2650 Hvidovre, Denmark.

Acta Chem. Scand. B 31 (1977) No. 10
A preliminary crystallographic study proved, that the proposed molecular structure was correct. It also gave the unexpected result that in the crystalline state all the three substituents on the chair-formed ring are placed in axial positions. Furthermore it was found, that the $N$-acetoxy groups are approximately planar with a cisoid arrangement of the $\mathrm{C}=\mathrm{O}$ and $\mathrm{N}-\mathrm{O}$ bonds. Jensen and Holm ${ }^{1}$ measured the dipole moment of the compound in dioxan to $3.25 \mathrm{D}$. This result implies that such conformers as described above can only contribute to a certain extent to the conformational equilibrium in solution. In order to get a better understanding of the molecular conformation adopted in the crystal structure a new set of X-ray data was collected, and a detailed refinement of the crystal structure was carried out.

\section{EXPERIMENTAL}

The title compound was prepared according to directions by Jensen and Holm. ${ }^{1}$ The crystals used for the X-ray experiments were grown by slowly evaporating a benzene solution at room temperature. Colourless, prismatic crystals were obtained.

Preliminary film investigations revealed monoclinic symmetry. Systematically absent reflections are $h k l$ when $h+k$ odd and $h 0 l$ when $l$ odd, the space group is thus $C c$ or $C 2 / c$. The unit-cell parameters were determined by a least-squares fit to the diffractometer measured $2 \theta$ angles for 27 reflections (see CRYSTAL DATA). The crystal density was measured 
by flotation in a chlorobenzene/bromobenzene mixture.

Three-dimensional diffraction data were measured at room temperature on a NONIUS three-circle automatic diffractometer using graphite monochromated MoK$\alpha$ radiation ( $\lambda=$ $0.71069 \AA)$. The $\omega$-scan technique with a scan speed of $1.2^{\circ} \mathrm{min}^{-1}$ was employed. Background counts were taken for half the scanning time at each of the scan range limits. All the data were measured from a single crystal with approximate dimensions $0.3 \times 0.4 \times 0.4 \mathrm{~mm}$. The crystal was sealed in a glass capillary and oriented with the $c$ axis parallel to the $\phi$ axis of the goniostat.

Due to instrumental difficulties the one standard reflection sampled every 50 intensity measurements showed two distinct intensity levels over the period of data collection. The data set was therefore divided into two parts each given a scale factor evaluated from the relative intensities of the standard. Of the 2772 unique reflections measured in the range $2.9 \leq \theta \leq 31.0^{\circ}, 1666$ had net intensities greater than $3.0 \sigma(I)$, where $\sigma(I)$ is the standard deviation from counting statistics. These were regarded as observed reflections and used in the refinement procedure. Lorentz and polarization corrections were applied, but no absorption corrections were made.
Structure solution and refinements. Normalized structure-factor amplitudes were calculated, and statistical tests indicated the presence of centres of symmetry; the space group was thus assumed to be $C 2 / c$. Phases were determined statistically for 117 reflections $(|E| \geq 1.5)$ following the modified symbolic addition pro. cedure used in the program system $X \cdot R A Y$ $72 .{ }^{2}$ An $E$ map constructed with these phases gave the positions of 16 non-hydrogen atoms of the molecule. The two remaining nonhydrogen atoms were localized by the use of successive Fourier refinements. Individual atomic parameters of this model were refined, first with isotropic and then anisotropic thermal parameters using the full-matrix least-squares method. The quantity minimized was $\sum\left(w\left|F_{0}\right|-\left|F_{c}\right|\right)^{2}$ where weights were taken as unity. After the refinement had converged, the six methylene hydrogen atoms were clearly located from a difference electron density map, whereas the map only showed diffuse clouds of electron density in the three areas where the methyl hydrogen atoms were expected to be situated. Refinement was continued varying two scale factors, the positional and anisotropic thermal parameters of the non-hydrogen atoms and the positional parameters of the six methylene hydrogen atoms (the thermal param. eters of the hydrogen atoms were fixed at

Table 1. Final positional and thermal $\left(\times 10^{2} \AA^{2}\right)$ parameters. The standard deviations are given in parentheses. The temperature factor is of the form: $\exp \left\{-2 \pi^{2}\left(h^{2} a^{* 2} U_{11}+k^{2} b^{* 2} U_{23}+l^{2} c^{* 2} U_{33}+2 h k a^{*} b^{*} U_{12}+2 h l a^{*} c^{*} U_{13}\right.\right.$ $\left.\left.+2 k l b * c * U_{23}\right)\right\}$

\begin{tabular}{|c|c|c|c|c|c|c|c|c|c|}
\hline Atom & $\boldsymbol{x}$ & $y$ & $z$ & $U_{11}$ & $U_{22}$ & $U_{33}$ & $U_{18}$ & $U_{13}$ & $U_{98}$ \\
\hline N1 & $.4520(1)$ & $.3985(1)$ & $.4520(2)$ & $4.69(11)$ & $3.60(10)$ & $5.24(11)$ & $-.11(8)$ & $1.16(8)$ & $-.81(8)$ \\
\hline $\mathrm{C} 2$ & $.4424(1)$ & $.4009(2)$ & $.5812(2)$ & $4.64(13)$ & $3.93(12)$ & 4.61(13) & $-.18(10)$ & $.35(10)$ & $-.97(10$ \\
\hline N3 & $.3724(1)$ & $.3613(1)$ & $.6041(2)$ & $4.95(11)$ & $3.63(10)$ & $4.32(10)$ & $-.22(8)$ & $.57(8)$ & $-.66(8)$ \\
\hline $\mathrm{C} 4$ & $.3090(1)$ & $.4013(2)$ & $.5107(2)$ & $4.49(13)$ & $4.75(14)$ & 4.74(13) & $.31(10)$ & $1.08(10)$ & $-.53(10$ \\
\hline N5 & $.3128(1)$ & $.4018(1)$ & $.3780(2)$ & $4.92(11)$ & $4.15(10)$ & $4.51(11)$ & $.18(8)$ & $.66(8)$ & $-.21(8)$ \\
\hline C6 & $.3859(1)$ & $.4356(2)$ & $.3625(2)$ & $5.77(14)$ & $4.00(13)$ & $4.79(14)$ & $.14(11)$ & $1.24(11)$ & $.04(11$ \\
\hline 011 & $.4658(1)$ & $.2909(1)$ & $.4228(2)$ & $5.06(9)$ & $3.74(9)$ & $6.38(10)$ & $-.07(7)$ & $1.22(7)$ & $-1.33(7)$ \\
\hline 012 & $.5831(1)$ & $.3419(2)$ & $.4259(2)$ & $5.53(11)$ & $6.42(13)$ & $9.51(15)$ & $.40(9)$ & $2.97(10)$ & $.97(10$ \\
\hline C11 & $.5379(1)$ & $.2755(2)$ & $.4205(2)$ & $5.48(15)$ & $5.24(15)$ & $3.78(12)$ & $.62(12)$ & $.95(10)$ & $-.25(10)$ \\
\hline $\mathrm{Cl2}$ & $.5532(2)$ & $.1628(2)$ & $.4116(3)$ & $8.03(19)$ & $5.92(17)$ & $6.94(18)$ & $1.77(14)$ & $1.45(15)$ & $-1.41(14)$ \\
\hline O31 & $.3701(1)$ & $.2489(1)$ & $.5865(1)$ & $5.75(10)$ & $3.85(8)$ & $4.29(9)$ & $-.32(7)$ & $.39(7)$ & $-.37(7)$ \\
\hline O32 & $.4235(1)$ & $.2352(2)$ & $.7936(2)$ & $8.36(14)$ & $7.21(13)$ & $4.39(10)$ & $-1.73(10)$ & $.12(9)$ & $.48(9)$ \\
\hline C31 & $.3976(1)$ & $.1960(2)$ & $.6946(2)$ & $3.83(12)$ & $5.15(14)$ & $5.39(15)$ & $-.35(10)$ & $.94(10)$ & $.57(12)$ \\
\hline C32 & $.3898(2)$ & $.0833(2)$ & $.6692(3)$ & $7.08(19)$ & $4.99(16)$ & $8.85(21)$ & $.25(13)$ & $.59(15)$ & $.63(14)$ \\
\hline 051 & $.3011(1)$ & $.2953(1)$ & $.3328(1)$ & $5.68(10)$ & $4.65(9)$ & $4.18(9)$ & $-.21(7)$ & $.20(7)$ & $-.58(7)$ \\
\hline O52 & $.2423(1)$ & $.3651(2)$ & $.1465(2)$ & $8.51(14)$ & $8.25(15)$ & $4.37(10)$ & $-.04(11)$ & $-.09(9)$ & $.36(10)$ \\
\hline C51 & $.2621(1)$ & $.2904(2)$ & $.2099(2)$ & $4.65(13)$ & $7.14(17)$ & $3.70(12)$ & $-.63(12)$ & $1.01(10)$ & $-.73(12)$ \\
\hline C52 & $.2494(2)$ & $.1804(2)$ & $.1717(3)$ & $6.68(17)$ & $7.52(20)$ & $6.00(16)$ & $-1.15(14)$ & $1.57(13)$ & $-2.33(14$ \\
\hline H21 & $.483(1)$ & $.364(2)$ & $.630(2)$ & 5.0 & & & & & \\
\hline H41 & $.263(1)$ & $.366(2)$ & $.517(2)$ & 5.0 & & & & & \\
\hline H61 & $.390(1)$ & $.420(2)$ & $.279(2)$ & 5.0 & & & & & \\
\hline H22 & $.445(1)$ & $.474(2)$ & $.604(2)$ & 5.0 & & & & & \\
\hline H42 & $.305(1)$ & $.477(2)$ & $.533(2)$ & 5.0 & & & & & \\
\hline H62 & $.386(1)$ & $.509(2)$ & $.377(2)$ & 5.0 & & & & & \\
\hline
\end{tabular}


isotropic values with $U=0.05 \AA^{2}$ ). After two cycles nine strong and five weak reflections which were considered to be affected by extinction and/or other factors were removed from the data set. A new difference synthesis again showed only diffuse electron density in the areas where the methyl hydrogen atoms were expected to be positioned. In the sub. sequent calculations the hydrogen atoms of each methyl group were introduced as two fixed sets each consisting of three hydrogen atoms with site occupational factors of 0.5 and isotropic temperature factors of $U=0.09 \AA^{2}$. The $\mathbf{C}-\mathbf{H}$ distances were taken as $1.0 \AA$, the $\mathrm{HCH}$ angles as $109.5^{\circ}$, and the torsion angle $\mathrm{O}=\mathrm{C}-\mathrm{C}-\mathrm{H}$ was arbitrarily fixed as $0^{\circ}$ in one set and as $60^{\circ}$ in the other. The leastsquares refinement was completed with the introduction of a weighting scheme of the form $w=1 /\left\{1+\left[\left(\left|F_{\mathrm{o}}\right|-19\right) / 18\right]^{2}\right\}$. On the last cycle of least-squares refinement the values of maximum and average shift/error were 0.05 and 0.01 , respectively. The final conventional $R$ value is 0.043 and $R_{\mathrm{w}}=0.052$ for 1652 unique reflections. A final difference synthesis showed no peaks or depressions greater than 0.2

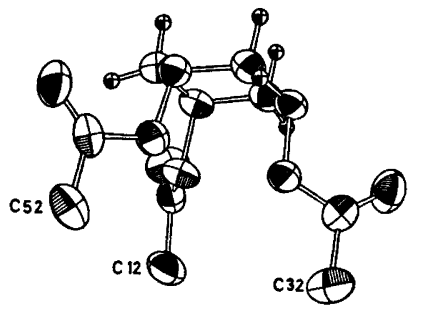

e $A^{-3}$. Table 1 lists the final positional and thermal parameters for the non-hydrogen atoms and six methylene hydrogen atoms. The terminal set of structure factors listed with the observed data are available by request.

The X-ray atomic scattering factors used were those of Cromer and Mann ${ }^{3}$ for $\mathrm{O}, \mathrm{N}$ and $\mathrm{C}$, and of Stewart, Davidson and Simpson ${ }^{4}$ for H. The computations were performed on an IBM 370/165 computer. The programs used were a local version of the NRC Picker Data Reduction Program, 5 the program system $X$. $R A Y 72,2$ and the drawing program ORTEP $I I .^{\circ}$

\section{CRYSTAL DATA}

1,3,5-Triacetoxyhexahydro-1,3,5-triazine, $\mathrm{C}_{9} \mathrm{H}_{15} \mathrm{~N}_{3} \mathrm{O}_{6}, \mathrm{M}=261.2$, m.p. $133{ }^{\circ} \mathrm{C}$. Space group $C 2 / c$ (No. 15); $a=18.448(4) \AA, b=12.991(3) \AA, c=10.860(8) \AA$, $\beta=103.31(3)^{\circ}, V=2517 \AA^{3}$, $Z=8, D_{\mathrm{m}}=1.37 \mathrm{~g} \mathrm{~cm}^{-3}, D_{\mathrm{x}}=1.378 \mathrm{~g} \mathrm{~cm}^{-3}$, $F(000)=1104, \mu(M \circ K \alpha)=1.25 \mathrm{~cm}^{-1}$.

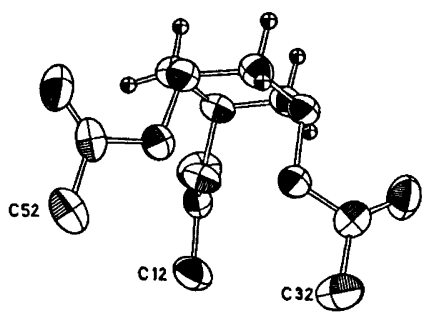

Fig. 1. Stereo view of the molecule.

Table 2. Bond lengths $(\AA)$ and valency angles $\left(^{\circ}\right)$ with estimated standard deviations in parentheses. The numbering of the atoms is indicated in Fig. 2.

\begin{tabular}{|c|c|c|c|c|c|c|c|c|}
\hline $\mathrm{N} 1-\mathrm{C}_{2}$ & \multicolumn{2}{|c|}{$1.454(3)$} & $\mathrm{Nl}-011$ & $1.461(2)$ & C11-012 & $1.189(3)$ & $\mathrm{C} 2-\mathrm{H} 21$ & $0.94(2)$ \\
\hline $\mathrm{C2}-\mathrm{N} 3$ & \multicolumn{2}{|c|}{$1.464(3)$} & $\mathrm{N3}-\mathrm{O} 31$ & $1.464(2)$ & $\mathrm{C} 31-\mathrm{O} 32$ & $1.185(3)$ & C4-H41 & $0.98(3)$ \\
\hline $\mathrm{N} 3-\mathrm{C} 4$ & \multicolumn{2}{|c|}{$1.455(3)$} & N5-O51 & $1.460(2)$ & $\mathrm{C} 51-\mathrm{O} 52$ & $1.193(3)$ & C6-H61 & $0.95(3)$ \\
\hline C4-N5 & \multicolumn{2}{|c|}{$1.459(3)$} & $011-\mathrm{C} 11$ & $1.351(3)$ & $\mathrm{C} 11-\mathrm{C} 12$ & $1.491(4)$ & $\mathrm{C} 2-\mathrm{H} 22$ & $0.97(3)$ \\
\hline $\mathrm{N} 5-\mathrm{C} 6$ & \multicolumn{2}{|c|}{$1.463(3)$} & $\mathrm{O} 31-\mathrm{C} 31$ & $1.352(3)$ & C31-C32 & $1.483(4)$ & $\mathrm{C} 4-\mathrm{H} 42$ & $1.02(3)$ \\
\hline $\mathrm{C} 6-\mathrm{N} 1$ & \multicolumn{2}{|c|}{$1.454(3)$} & $\mathrm{O} 51-\mathrm{C} 51$ & $1.364(3)$ & $\mathrm{C} 51-\mathrm{C} 52$ & $1.483(4)$ & C6-H62 & $0.96(3)$ \\
\hline \multicolumn{2}{|c|}{$\mathrm{C} 6-\mathrm{N} 1-\mathrm{C} 2$} & $111.6(2)$ & \multicolumn{2}{|c|}{$\mathrm{N} 1-011-\mathrm{C} 11$} & $111.4(2)$ & \multicolumn{2}{|c|}{$\mathrm{H} 21-\mathrm{C} 2-\mathrm{N} 1$} & $106(2)$ \\
\hline \multicolumn{2}{|c|}{$\mathrm{N} 1-\mathrm{C} 2-\mathrm{N} 3$} & $117.7(2)$ & & $\mathrm{N} 3-\mathrm{O} 31-\mathrm{C} 31$ & $113.1(2)$ & \multicolumn{2}{|c|}{$\mathrm{H} 21-\mathrm{C} 2-\mathrm{N} 3$} & $110(2)$ \\
\hline \multicolumn{2}{|c|}{$\mathrm{C} 2-\mathrm{N} 3-\mathrm{C} 4$} & $110.9(2)$ & & $\mathrm{N} 5-051-\mathrm{C51}$ & $112.1(2)$ & \multicolumn{2}{|c|}{$\mathrm{H} 41-\mathrm{C} 4-\mathrm{N} 3$} & $111(1)$ \\
\hline \multicolumn{2}{|c|}{$\mathrm{N} 3-\mathrm{C} 4-\mathrm{N} 5$} & $118.5(2)$ & & $011-\mathrm{C} 11-012$ & $125.2(2)$ & \multicolumn{2}{|c|}{ H41-C4-N5 } & $108(1)$ \\
\hline \multicolumn{2}{|c|}{$\mathrm{C} 4-\mathrm{N} 5-\mathrm{C} 6$} & $111,7(2)$ & & $\mathrm{O} 31-\mathrm{C} 31-\mathrm{O} 32$ & $124.4(2)$ & \multicolumn{2}{|c|}{$\mathrm{H} 61-\mathrm{C} 6-\mathrm{N} 1$} & $109(1)$ \\
\hline \multicolumn{2}{|c|}{$\mathrm{N} 5-\mathrm{C} 6-\mathrm{N} 1$} & $118.6(2)$ & & $\mathrm{O} 51-\mathrm{C51}-\mathrm{O52}$ & $123.4(2)$ & \multicolumn{2}{|c|}{$\mathrm{H} 61-\mathrm{C} 6-\mathrm{N} 5$} & $9(1)$ \\
\hline $\mathrm{C2}-\mathrm{Nl}$ & & & 011 & $\mathrm{Cl1}-\mathrm{C12}$ & $110.3(2)$ & H22 & $-\mathrm{Nl}$ & $5(1)$ \\
\hline C6-N1 & & & O31 & $\mathrm{C} 31-\mathrm{C32}$ & $109.5(2)$ & $\mathrm{H} 22$ & -N3 & $6(1)$ \\
\hline $\mathrm{C} 2-\mathrm{N} 3$ & & & 051 & $\mathrm{C} 51-\mathrm{C} 52$ & $109.4(2)$ & H42 & $-\mathrm{N3}$ & $5(1)$ \\
\hline $\mathrm{C} 4-\mathrm{N} 3$ & & & 012 & $\mathrm{C} 11-\mathrm{C12}$ & $124.5(3)$ & H42 & -N5 & $5(1)$ \\
\hline C4-N5 & & 10 & 032 & C31-C32 & $126.1(2)$ & H62 & $-\mathrm{Nl}$ & $4(1)$ \\
\hline C6-N5 & & 10 & 052 & $\mathrm{C51}-\mathrm{C52}$ & $127.3(2)$ & H62 & -N5 & 4(1) \\
\hline H21 - & 122 & 11 & H41 & - C4-H42 & $108(2)$ & H61 & $-\mathbf{H 6 2}$ & $2(2)$ \\
\hline
\end{tabular}

Acta Chem. Scand. B 31 (1977) No. 10 


\section{RESULTS AND DISCUSSION}

Molecular constitution. A stereo view of a single molecule as found in the crystal structure is shown in Fig. 1. The bond lengths and valency angles are given in Table 2. These results definitely prove the molecular formula $1,3,5$ - triacetoxyhexahydro-1,3,5-triazine advocated by Jensen and Holm ${ }^{1}$ for triacetylated "triformoxime".

Average molecular dimensions. The lengths of the chemically equivalent bonds are found to be almost identical with one another in the crystal structure determination. A good a-

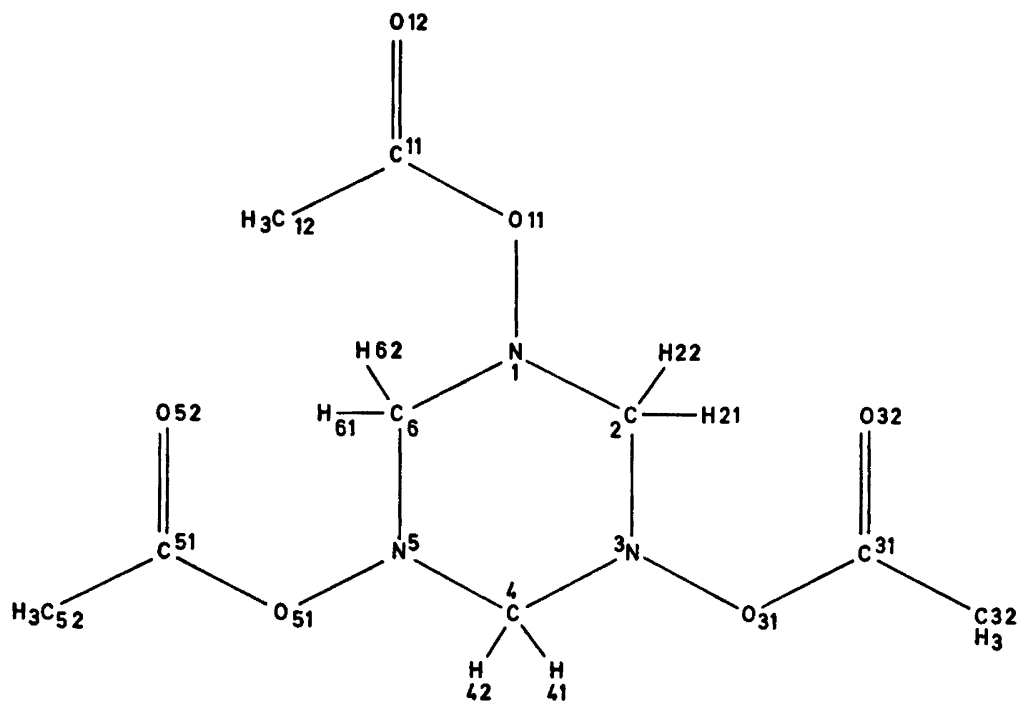

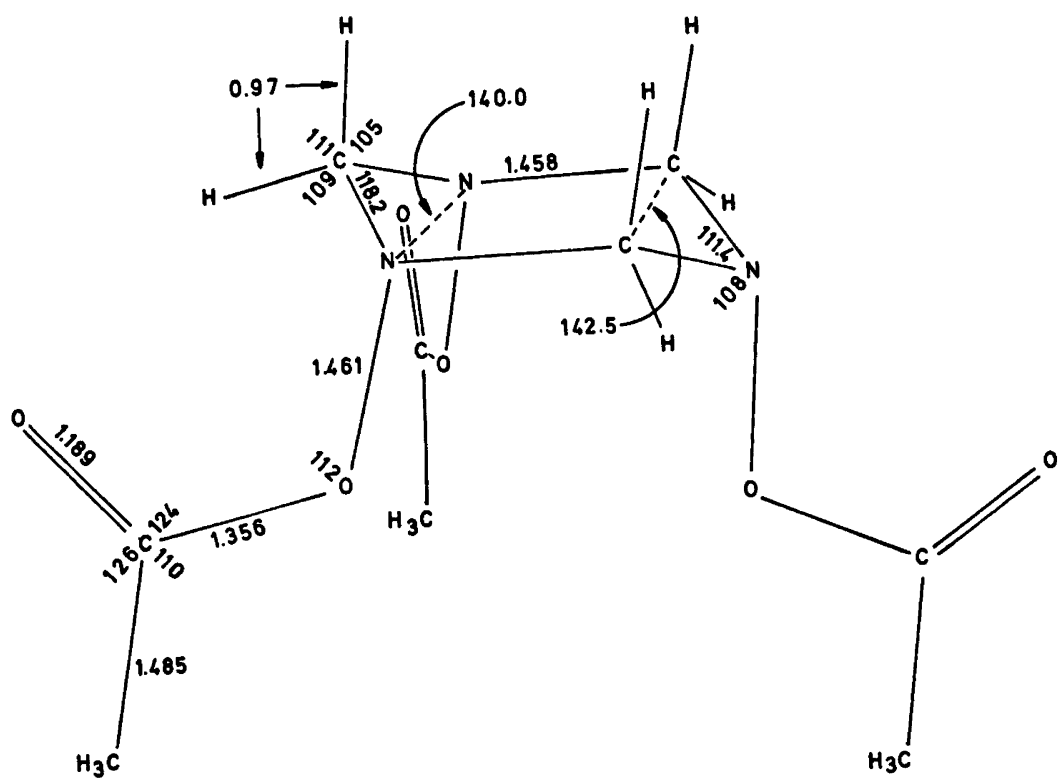

Fig. 2. (a) Numbering of the atoms; the even-numbered methylene hydrogen atoms are axial. (b) Average dimensions of the molecule (in $\AA$, resp..$^{\circ}$ ). 
greement is also observed between chemically equivalent bond angles, except the six CNO angles, which deviate up to $2.2^{\circ}$ from the mean value. The conformation of the heterocyclic ring is not quite regular as indicated by deviations of the individual torsion angles up to $2.6^{\circ}$ from the average value $43.7^{\circ}$. These torsion angles and the exocyclic CNO angles are, however, likely to be appreciably influenced by the packing of the molecules in the crystal, and the variations found are not considered to reflect any difference inherent in the molecular structure.

In the following discussion reference is made to an average molecule, which is defined by the average values of the chemically equivalent bond distances and valency angles. By this definition the average conformation of the heterocyclic ring is defined. The conformation is given either as the average torsion angle or as the average values for the two dihedral angles CNC-CCNN and NCN-NNCC. The average dimensions of the molecule are given in Fig. 2, in which the numbering of the atoms used in the description is also indicated.

The hexahydro-1,3,5-triazine ring. Blackburne et al. ' have calculated the ring-conformation with minimum strain energy for a number of six-membered, saturated rings. In calculating this "ideal conformation" for hexahydro-1,3,5triazine an invariant $\mathrm{C}-\mathrm{N}$ distance of $1.47 \AA$ was assumed, and the angle between the lone pair and the exocyclic bond was taken to be $113^{\circ}$ and bisected by the CNC plane.

The crystal structures of two 1,3,5-trisubstituted hexahydro-1,3,5-triazines have previously been reported, viz. that of the triacetyl derivative, "TRAT"' and that of the trinitro derivative, "RDX".? The average dimensions of the rings found in these two structures together with those of the present molecule and of the "ideal conformation" are given in Table 3.

In the TRAT molecule the three bonds from each ring-nitrogen atom are nearly coplanar owing to the amide character of the nitrogen atoms. The molecule has a pseudo threefold symmetry. From Table 3 it can be seen that the conformation of the ring is only slightly distorted from that of the ideal one. This is in accordance with the facts that the acetyl groups do not sterically interfere with one another, and that there are no strong intermolecular interactions.

In the RDX molecule a pseudo mirror plane is found. The substituents are arranged with one nitro group in a distorted equatorial position and the other two nitro groups in distorted axial positions. The ring is considerably distorted compared to the ideal conformation, see Table 3 . The CNC angle is expanded about $3^{\circ}$, and though the average magnitude of the NCN angles is as in the ideal ring, the individual values vary considerably. This irregularity is reflected in the large fluctuations of the torsion angles. The strong intra-molecular interaction between the oxygen atoms of the nitro groups and the methylene groups of the ring ${ }^{9}$ is presumably the main cause of the ring distortion, though some rather short inter-molecular contacts are also found in the crystal structure.

The heterocyclic ring in the present structure is in a flattened chair conformation with an average torsion angle of $43.7^{\circ}$. The $\mathrm{C}-\mathrm{N}$ bond distances agree well with those found in TRAT (X-ray diffraction study) and in RDX (neutron diffraction study). All the $\mathrm{N}$-substituents are in axial positions. The conformation of the average ring as compared to the "ideal conformation" is characterized by a large expansion

Table 3. Conformation of some hexahydro-1,3,5-triazine rings. The average values of some ohemically equivalent angles and bond lengths are indicated with the maximum deviation of the individual values in square brackets.

\begin{tabular}{|c|c|c|c|c|c|c|}
\hline Compound & $\mathrm{C}-\mathrm{N}(\AA)$ & $\begin{array}{l}\text { Angle } \\
\mathrm{C}-\mathrm{N}-\mathrm{C}\end{array}$ & $\begin{array}{l}\text { Angle } \\
\mathrm{N}-\mathrm{C}-\mathrm{N}\end{array}$ & $\begin{array}{l}\text { Torsion } \\
\text { angle }\end{array}$ & $\begin{array}{l}\text { Dihedral angl } \\
\text { CNC-CCNN }\end{array}$ & NCN-NNCC \\
\hline "Ideal ring"” & $(1.47)$ & 111.5 & 109.2 & 57.7 & 127.2 & 128.3 \\
\hline Present structure & $1.458[.006]$ & $111.4[.5]$ & $118.2[.5]$ & $43.7[2.6]$ & $142.5[1.7]$ & $140.0[1.7]$ \\
\hline TRAT $^{3}$ & $1.455[.012]$ & $111.1[.4]$ & $110.4[.9]$ & $51.4[1.5]$ & & \\
\hline $\mathrm{RDX}^{2}$ & $1.454[.014]$ & $114.8[.3]$ & $109.3[2.4]$ & $47.6[5.7]$ & & \\
\hline
\end{tabular}

Acta Chem. Scand. B 31 (1977) No. 10 


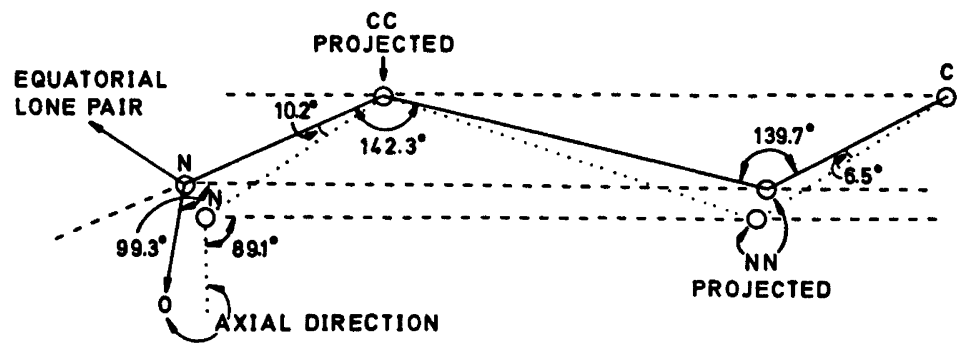

Fig. 3. Section through a superposition of the ideal conformation of the hexahydro-1,3,5-triazine ring (dotted lines) and a conformation derived from the ideal one by expanding the angle $\mathrm{N}-\mathrm{C}-\mathrm{N}$ to $118.2^{\circ}$ (full lines). $C f$. the observed average values of the dihedral angles given in Table 3.

of the NCN angle, whereas the CNC angle is unchanged. This conformation can be derived from the ideal geometry by rotating each of the three nitrogen atoms through an angle of $10.2^{\circ}$ outwards about an axis connecting the adjacent carbon atoms, see Fig. 3. Presuming the same angular distribution of the valencies and the lone pair of the nitrogen atoms as in the ideal ring, calculations give a corresponding $\mathrm{CNO}$ angle $=108.2^{\circ}$ and for an $\mathrm{N}-\mathrm{O}$ bond $=1.46$ $\AA$ an $\mathrm{O}_{\text {axial }} \cdots \mathrm{O}_{\text {axial }}$ distance of $2.91 \AA$, i.e. slightly longer than twice the van der Waals radius of oxygen. These values are very close to the average values found in the crystal structure determination, viz. the CNO angle $108^{\circ}$ and $O_{\text {axial }} \cdots O_{\text {axial }}=2.87 \AA$ (the measured values are $011 \cdots 031=2.83,011 \cdots 051=2.97$, and $031 \cdots 051=2.82 \AA$ ). The average conformation of the hexahydro-1,3,5-triazine ring found in the present crystal structure thus represents a distortion of the ideal ring, which just allows the accommodation of three axial oxygen atoms attached to the nitrogen atoms.

The $\mathrm{N}$-acetoxy groups. The conformations of the $N$-acetoxy groups are given by the respective torsion angles $\mathrm{N}-\mathrm{O}-\mathrm{C}=\mathrm{O}$ and $\mathrm{C}_{\text {ring }}$ $\mathrm{N}-\mathrm{O}-\mathrm{C}$ (Table 4). The $\mathrm{N}$-acetoxy groups at N5 and N3 are approximately planar, whereas the N1-acetoxy group deviates more from planarity. The three $N$-acetoxy groups are unsymmetrically oriented with respect to the hexahydrotriazine ring; the best plane through the N5-acetoxy group points roughly at atom $\mathrm{N} 3$, and the corresponding N3-plane is directed towards N5, whereas the best plane through the N1-acetoxy group is directed towards the central part of the ring, of. Fig. 1.
Table 4. Selected torsion angles $\left({ }^{\circ}\right)$.

\begin{tabular}{lr} 
C11-O11-N1-C2 & $\mp 106.4(2)$ \\
C11-O11-N1-C6 & $\pm 132.5(2)$ \\
O12-C11-O11-N1 & $\mp 8(3)$ \\
C31-O31-N3-C2 & $\pm 91.8(2)$ \\
C31-O31-N3-C4 & $\mp 149.2(2)$ \\
O32-C31-O31-N3 & $\mp \quad 2.3(3)$ \\
C51-O51-N5-C6 & $\mp 95.0(2)$ \\
C51-O51-N5-C4 & $\pm 144.6(2)$ \\
O52-C51-O51-N5 & $\pm 2.3(3)$ \\
\hline
\end{tabular}

The average $\mathrm{N}-\mathrm{O}$ distance is identical to the $\mathrm{N}-\mathrm{O}$ distance $1.458(5) \AA$ found in $O$ carbamoylhydroxylamine. ${ }^{10}$ The remaining dimensions of the $N$-acetoxy group and the $N$-carbamoyloxy group are not comparable. The average $O$-acyl dimensions found in the present structure determination agree with the average results of a crystal structure study of four N,O-dibenzoylhydroxylamines (having methyl-, chloro- or no substituents in the benzene rings)."1 The cisoid position of the $\mathrm{C}=\mathrm{O}$ and the $\mathrm{O}-\mathrm{N}$ bond found in the present structure is also found in the $N$-acyloxy groups of these four $\mathrm{N}, \mathrm{O}$-dibenzoylhydroxylamines ${ }^{11}$ as well as in some $O$-acyloximes..$^{12,13}$

The molecular packing. The packing of the molecules may be described as a layer structure in which all hydrogen atoms are situated near the surfaces of the layers. The layers are running parallel to the ac-plane, their crosssection being about $\frac{1}{2} b$. In Fig. 4 two such layers are shown. The axial hydrogen atoms are sticking out of the layers, whereas the acetoxy groups are situated in the interior.

Acta Chem. Scand. B 31 (1977) No. 10 

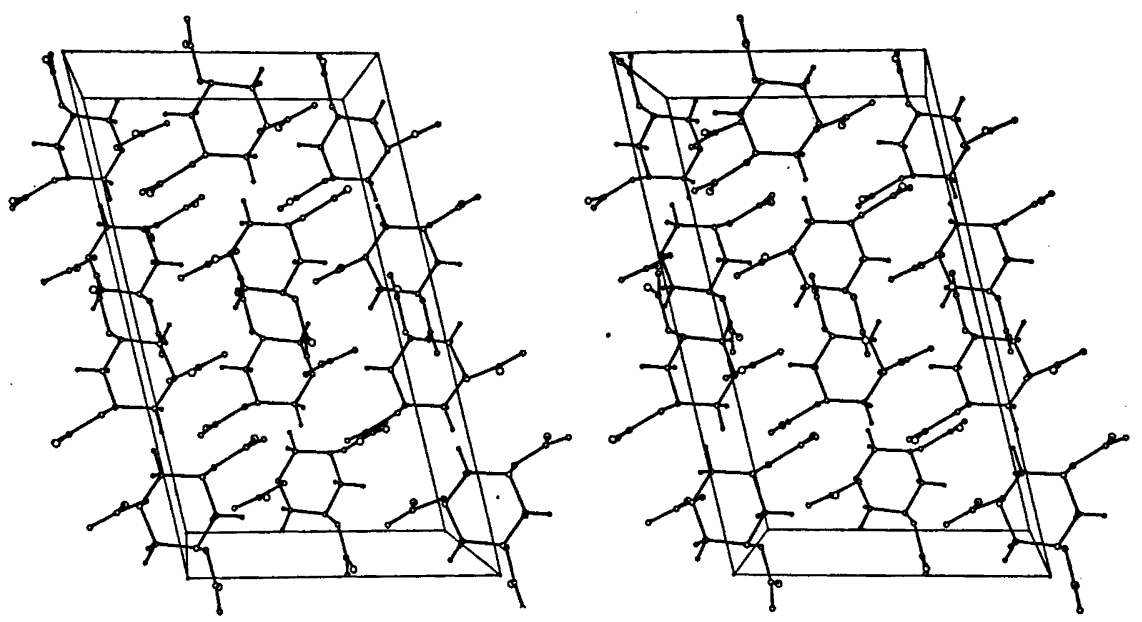

Fig. 4. Stereo diagram illustrating the molecular packing. The view is down the $b$ axis, $a \uparrow$ and $c \rightarrow$

Table 5. Inter-molecular distances, non $\mathrm{H}-$ non $\mathrm{H}<3.5 \AA$, non $\mathrm{H}-\mathrm{H}_{\text {methylene }}<3.0 \AA$. The distances are given between a molecule with the parameters $x, y, z$ as in Table 1 and molecules related by symmetry operations $\overline{1}$ (in $0,0,0), 2$ (in $0, y, \downarrow)$ or $c$ (in $x, 0, z$ ) combined with translations along the axial directions.

Symmetry operation + translation

Inter-molecular distances within a layer
Non $\mathrm{H}-$ non $\mathrm{H}$ distances $<3.5 \AA$
Non $\mathbf{H}-\mathrm{H}_{\text {methylene }}<3.0 \AA$

\begin{tabular}{|c|c|c|c|}
\hline $2+1,0,1$ & $\begin{array}{l}\mathrm{O} 32 \cdots \mathrm{O} 11 \\
\mathrm{O} 32 \cdots \mathrm{C} 11 \\
\mathrm{O} 22 \cdots \mathrm{O} 12 \\
\mathrm{O} 32 \cdots \mathrm{C} 12 \\
\mathrm{O} 32 \cdots \mathrm{C} 31 \\
\mathrm{O} 32 \cdots \mathrm{O}_{2} \\
\mathrm{O} 32 \cdots \mathrm{C} 2\end{array}$ & \begin{tabular}{|l|}
3.36 \\
$\mathbf{3 . 0 7}$ \\
$\mathbf{3 . 3 7}$ \\
$\mathbf{3 . 2 7}$ \\
$\mathbf{3 . 3 1}$ \\
$\mathbf{3 . 1 8}$ \\
$\mathbf{3 . 3 2}$
\end{tabular} & $\mathrm{O} 32 \cdots \mathrm{H} 2 \mathrm{I}$ \\
\hline$\overline{1}+\frac{1}{2}, \frac{1}{2}, 1$ & 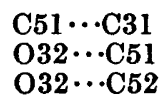 & $\begin{array}{l}3.35 \\
3.43 \\
3.47\end{array}$ & 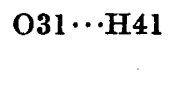 \\
\hline $2+1,0,0$ & & & $\mathrm{O} 12 \cdots \mathrm{H} 61$ \\
\hline \multicolumn{4}{|c|}{ Inter-molecular distances between neighbouring layers } \\
\hline$\overline{1}+1,1,1$ & $\begin{array}{l}\mathrm{N} 1 \cdots \mathrm{N} 1 \\
\mathrm{~N} 1 \cdots \mathrm{C} 2 \\
\mathrm{O} 12 \cdots \mathrm{C} 2\end{array}$ & $\begin{array}{l}3.20 \\
3.31 \\
3.35\end{array}$ & $\begin{array}{l}\mathrm{N} 1 \cdots \mathrm{H} 22 \\
\mathrm{O} 12 \cdots \mathrm{H} 62 \\
\mathrm{O} 12 \cdots \mathrm{H} 22\end{array}$ \\
\hline$c+0,1, \overline{1}$ & & & $\mathrm{O} 52 \cdots \mathrm{H} 42$ \\
\hline
\end{tabular}

The shortest inter-molecular distances are given in Table 5. There are no short contacts between the molecules. The most prominent inter-molecular interactions are formed between two molecules placed in the same layer and related by a two-fold axis (the equivalent positions $x, y, z$ and $1-x, y, 3 / 2-z$ are seen in
Fig. 4). It is inferred, that these contacts are largely responsible for the conformation adopted by the acetoxy groups in the crystal structure. Furthermore several inter-molecular carbonyl oxygen - hydrogen distances in the range 2.4$2.8 \AA$ should be mentioned. These distances involve methylene hydrogen atoms as indicated

Acta Chem. Scand. B 31 (1977) No. 10 
in Table 5, and also methyl hydrogen atoms; the precise values of the latter distances cannot be given owing to the conformational disorder of the methyl groups. The corresponding many, albeit weak, polar attractions may contribute significantly to stabilize the crystal structure.

Acknowledgements. The financial support from "Statens almindelige Videnskabsfond", "Carlsbergfondet" and "Statens naturvidenskabelige Forskningsråd" is gratefully acknowledged.

\section{REFERENCES}

1. Jensen, K. A. and Holm, A: K. Dan. Vidensk. Selsk., Mat.-Fys. Medd. Vol. 40 No. 1. In press.

2. X-RAY System 72, Technical Report TR192, Computer Science Center, University of Maryland, College Park 1972.

3. Cromer, D. T. and Mann, J. B. Acta Crystallogr. A 24 (1968) 321.

4. Stewart, R. F., Davidson, E. R. and Simpson, W. T. J. Chem. Phys. 42 (1965) 3175 .

5. Ahmed, F. R. NRC Crystallographic Program System, National Research Council Ottawa, Canada 1968.

6. Johnson, C. K. ORTEP II, Report ORNL3794, revised 1971, Oak Ridge National Laboratory, Oak Ridge.

7. Blackburne, I. D., Duke, R. P., Jones, R. A. Y., Katritzky, A. R. and Record, K. A. F. J. Chem. Soc. Perkin Trans. 2 (1973) 332.

8. Choi, C. S., Santoro, A. and Marinkas, P. L. Acta Crystallogr. B 31 (1975) 2934.

9. Choi, C. S. and Prince, E. Acta Crystal. logr. $B \quad 28$ (1972) 2857.

10. Larsen, I. K. Acta Chem. Scand. 22 (1968) 843.

11. Göttlicher, S. and Ochsenreiter, P. Chem. Ber. 107 (1974) 398.

12. Fischmann, E., MacGillavry, C. H. and Romers, C. Acta Crystallogr. 14 (1961) 753 and 759 .

13. Kerr, K. A., Robertson, J. M. and Sim, G. A. J. Chem. Soc. B (1967) 1305.

Received July 4, 1977. 